\section{Pablo Zunino**}

Resumo: Este artigo examina algumas aproximações e distanciamentos de Merleau-Ponty em relação à filosofia de Bergson, tendo em vista que Merleau-Ponty parece dividido quanto ao seu parecer sobre a concepção bergsoniana do tempo. Essa oscilação entre crítica e elogio é certamente visível na Fenomenologia da percepção, na qual Merleau-Ponty reconhece que Bergson teria dissolvido a questão do dualismo ao afirmar que "o corpo e o espírito se comunicam pela mediação do tempo". Entretanto, Merleau-Ponty vai denunciar outra espécie de dualismo bergsoniano, que pretende reencontrar a unidade na multiplicidade por meio do conceito de "multiplicidade de fusão". Nesse sentido, a metáfora bergsoniana da "bola de neve" procura caracterizar a essência do tempo enquanto duração.

Palavras-chave: Merleau-Ponty, Bergson, temporalidade, dualismo, subjetividade.

\section{Introdução}

Merleau-Ponty desenvolve o tema da "temporalidade", numa passagem do capítulo homônimo da Fenomenologia da percepção que começa assim: "Apliquemos a idéia da subjetividade como temporalidade aos problemas pelos quais começamos" (Merleau-Ponty 4, p. 492). Assim, o problema da relação entre a alma e o corpo remete à questão de "saber como um ser que é porvir e passado tem também um presente" (Ibid.). Todavia, pensamos que Merleau-Ponty retoma, certamente através de uma inflexão importante, aquilo que para Bergson era uma conservação automática do passado. Merleau-Ponty, então, vai reivindicar um "tempo verdadeiro", no qual apreendemos a passagem e o próprio trânsito. Mas essa ressonância bergsoniana de um tempo que mantém tudo a encontramos primeiramente no capítulo sobre o "corpo":

"O presente ainda conserva em suas mãos o passado imediato, sem pô-lo como objeto, e, como este retém da mesma maneira o passado

* Texto originalmente apresentado como comunicação de pesquisa durante a Jornada "Merleau-Ponty e o Grande Racionalismo". São Paulo: FFLCH-USP, 2008.

** Doutorando USP / CNPq
Depois, no capítulo sobre o "cogito”, Merleau-Ponty examina o fenômeno da linguagem e mostra como um pensamento "adquirido" pode ser considerado intemporal. Para explicitar essa "aquisição para sempre", o autor lança mão do modelo da temporalidade, pois dizer que um acontecimento temporal tem lugar quer dizer que este "será verdadeiro pra sempre" (Merleau-Ponty 4, p.450 [525]). A "pirâmide de passado", que Merleau-Ponty toma de empréstimo de Proust para ilustrar o fenômeno irredutível da aquisição, projeta atrás de si o "cone”, que Bergson descreve em Matéria e memória, como a sombra reveladora do argumento filosófico:

“Aquilo que vivemos é e permanece perpetuamente para nós, o velho toca sua infância. Cada presente que se produz crava-se no tempo como uma cunha e pretende a eternidade. A eternidade não é uma outra ordem para além do tempo, ela é a atmosfera do tempo" (Merleau-Ponty 4, pp. 450-451 [p.526]).

Julgamos que uma investigação sobre as tensões entre ambos os filósofos, sejam elas aproximações ou distanciamentos, nos permitirá distinguir o que é que MerleauPonty retoma de Bergson e o que é modificado. Contudo, num primeiro momento, nosso trabalho será mais humilde e embrionário, na exata medida em que pretendemos alinhar aqui algumas notas que preparem o terreno para um estudo frutífero sobre a convergência no pensamento desses dois autores.

\section{$* * *$}

Como se sabe, o projeto fenomenológico de Merleau-Ponty está inserido no propósito geral da fenomenologia husserliana de voltar às próprias coisas, isto é, de reencontrar a camada originária da relação da consciência consigo mesma e com o mundo. Nesse sentido, a noção de correlação estabelece uma reciprocidade entre sujeito e objeto que faz com que a consciência e os conteúdos do mundo sejam correlatos, de modo 
que não pode existir um sem o outro. Assim, a grande contribuição de Husserl consiste em mostrar que consciência e subjetividade significam movimento intencional. Todavia, a concepção husserliana de um sujeito universal situado fora do mundo (subjetividade transcendental) foi abandonada por Merleau-Ponty ao procurar unir num mesmo solo o empírico e o campo fenomenal, adotando o corpo como sendo o novo sujeito da percepção. Bento Prado Jr. sugere que essa guinada no projeto merleau-pontyano anuncia certa influência da reflexão bergsoniana, marcada pela recusa inicial de emprestar ao mundo o caráter de um sistema de objetos que se desata diante de um impassível sujeito teórico, transmundano e "não-situado" (Cf. Prado Jr. 8).

Bergson, por sua vez, também propõe um retorno aos dados imediatos que deve pautar-se pela consideração de um dado fundamental da realidade, a saber, o tempo ou a temporalidade presente na realidade subjetiva e objetiva. Assim, Bergson vai procurar uma via para a compreensão da subjetividade sem limitar-se à abordagem na interface interioridade-exterioridade, pois a consciência não é mais considerada como um dado a priori e sim como resultado de um processo que tampouco se constitui a partir de uma estrutura intencional. Trata-se de uma consciência que é constituída pelo "campo transcendental" das imagens sem, no entanto, constituí-lo. Desse modo, a relação entre sujeito e objeto é concebida por Bergson a partir de um "campo de imagens" anterior à própria relação. Esse "campo transcendental”, como foi chamado por Bento Prado Jr, mostra como se dá o nascimento da subjetividade no corpo próprio, isto é, na corporeidade interiorizada ou na presença corporal. Por esse viés, o problema da relação entre espírito e matéria também recebe um tratamento adequado, visto que se trata do surgimento, no seio da matéria, da percepção da própria matéria. Esse processo de constituição da subjetividade deve ser compreendido como finitude ou como empobrecimento da Presença. Evidentemente, essas análises bergsonianas exerceram uma enorme influência no pensamento de Merleau-Ponty, sobretudo na noção de mundo pré-objetivo ou préreflexivo. Com isso, ele pode deslocar o papel do sujeito na fenomenologia, que seria ainda preponderante e estaria dentro da tradição moderna das "filosofias da subjetividade". Mas a relação entre subjetividade e temporalidade que se estabelece na fenomenologia de Merleau-Ponty não deriva necessariamente dessa inspiração bergsoniana, pois o próprio Husserl já havia introduzido as noções de "campo de presença” ou "presente vivo" na sua obra Para uma fenomenologia da consciência do tempo interior. ${ }^{3}$

Não obstante, como também observa Damon Moutinho, Merleau-Ponty define um projeto de filosofia distinto daquele que poderia ser caracterizado como uma "fenomenologia da razão". Para ele, o estatuto da reflexão e a experiência do irrefletido devem considerar-se à luz da noção de "acontecimento" evidenciando ainda mais a presença de Bergson na letra de Merleau-Ponty:

"Merleau-Ponty não deixa de notar que é o modelo bergsoniano que supõe, não mais que o sujeito absorva o objeto, como o modelo reflexivo, mas, ao contrário, que o sujeito se dilate até se confundir com o objeto (...): não é o ser que é reduzido a um correlato e absorvido pelo saber; é o saber que se expande até o sujeito fundirse ao ser" (Moutinho 7, p.14).

É importante notar que para Merleau-Ponty a noção de acontecimento não tem lugar no "mundo objetivo", já que este é desprovido seja do passado seja do futuro. No mundo objetivo, a única dimensão temporal que existe é aquela do presente. Daí a crítica de Merleau-Ponty à célebre passagem de Heráclito, que compara o curso do tempo ao curso de um rio: o tempo escoaria do passado para o presente e do presente para o futuro. Mas essa comparação é muito confusa (Cf. Merleau-Ponty 4, p.470), dirá Merleau-Ponty. Os acontecimentos tais como a formação da neve no alto da montanha, o seu derretimento, a formação da água, e assim por diante, são recortes do mundo objetivo, mas a própria noção de "acontecimento" não teria sentido sem a presença de alguém a quem alguma coisa acontecesse. O tempo supõe necessariamente um sujeito, por isso a metáfora do rio deve adicioná-lo sub-repticiamente como um observador implícito, de modo que para Merleau-Ponty, o tempo não pode ser — como acredita Bergson — um "processo real", senão algo que "nasce de minha relação com as coisas":

"Não é o passado que empurra o presente nem o presente que empurra o futuro para o ser; o porvir não é preparado atrás do observador, ele se premedita em frente dele, como a tempestade no horizonte" (Merleau-Ponty 4, p. 470-471 [551]). 
Contudo, Merleau-Ponty aceita a tese da equivalência bergsoniana entre corpo e presente, e espírito e escoamento do tempo (passado, futuro). O caminho tradicional, trilhado por Descartes ao tratar da união da alma e do corpo, era antes em termos espaciais do que temporais. Isso porque ele opõe radicalmente o extenso (corpo) ao inextenso (alma). Dessa oposição inicial entre contraditórios provém a obscuridade da questão. $\mathrm{Na}$ hipótese dualista, a matéria é vista como espacialmente divisível, ao passo que os estados de consciência (alma) são rigorosamente inextensos. Assim, corta-se de saída qualquer comunicação entre ambos os termos. O erro do dualismo vulgar, apontado por Bergson, é situar-se no ponto de vista do espaço e situar as sensações inextensas na consciência, tornando incompreensível a comunicação entre o corpo e o espírito. E o que faz Bergson? Ele substitui o "código espacial" pelo "código temporal", ou seja, mostra que a matéria pode ser compreendida por nós como uma sucessão de momentos ou de movimentos rápidos, separando-se assim da sua espacialidade. As diversas cores, por exemplo, são determinadas freqüências recolhidas por nossa percepção no campo transcendental. Nessa medida, a "ação virtual" passa a ser entendida como expressão da nossa capacidade de agir:

“É essa ação virtual que extrai da matéria nossas percepções reais, informações das quais necessita para se guiar, condensações, num instante de nossa duração, de milhares, de milhões, de bilhões de acontecimentos que se realizam na duração muitíssimo menos tensionada das coisas" (Bergson 3, p. 64).

O espírito, por sua vez, passa a ser compreendido como memória, isto é, progresso, evolução, permitindo que os dois termos sejam capazes de se unir. No "código espacial", a matéria é aquilo que está no espaço e o espírito aquilo que está fora do espaço. Porém, no código temporal, existem infinidades de graus entre matéria e espírito, os quais, por isso, não apresentam diferenças qualitativas. Portanto, pode haver união entre corpo e alma:

"Entre as qualidades sensíveis consideradas em nossa representação e essas mesmas qualidades tratadas como mudanças calculáveis, há portanto apenas uma diferença de ritmo de duração, uma diferença de tensão interior. Assim, através da idéia de tensão procuramos suspender a oposição da qualidade à quantidade, como, através da idéia de extensão, a do inextenso ao extenso. Extensão e tensão admitem graus múltiplos, mas sempre determinados. A função do entendimento é retirar desses dois gêneros, extensão e tensão, seu recipiente vazio, isto é, o espaço homogêneo e a quantidade pura, substituir deste modo realidades flexíveis, que compolrtam graus, por abstrações rígidas, nascidas das necessidades da ação" (Bergson 1, p. 289). ${ }^{5}$

Merleau-Ponty retoma a substituição bergsoniana do código espacial pelo código temporal ao reconhecer uma diferença de grau e não de natureza entre matéria e espírito. Mas a questão está em saber se Bergson ainda conserva algo do dualismo ao fazer essa "substituição". Ora, a prerrogativa do tempo não significa conservação do dualismo, porque Bergson não está apenas substituindo o espaço pelo tempo, ou um código por outro. O que é preciso ressaltar é que essa leitura que Merleau-Ponty faz da substituição dos códigos o aproxima de Bergson ao aproximá-lo do monismo (graus de tensão da duração). Essa convergência, observada na Fenomenologia da percepção, pode ser afirmada de forma independente dos desenvolvimentos posteriores, apelandose para os cursos em que a questão é retomada. O tratamento crítico que Bergson dá aos dualismos não consiste em conservar a dualidade e mudar a escolha dos termos. Por isso, não se pode falar em Bergson da "unidade" do tempo por oposição à multiplicidade.

Todavia, Merleau-Ponty recusa a noção bergsoniana de "multiplicidade de fusão ou de interpenetração", pois essa noção estaria presa a um quadro dualista e naturalista: "se trata ainda de dois gêneros de ser. Apenas se substitui a energia mecânica por uma energia espiritual". Mas o principal motivo dessa recusa merleau-pontiana da multiplicidade de fusão é a tentativa bergsoniana de reencontrar a unidade na multiplicidade, visto que esta noção faz evaporar a multiplicidade na unidade. Se o tempo é compreendido como multiplicidade de fusão, ele se evapora, pois falta a multiplicidade: "se, em virtude do princípio de continuidade, o passado pertence ainda ao presente e o presente já é do passado, não há nem presente nem passado; se a consciência faz bola de neve $e^{6}$ consigo mesma, ela estará como a bola de neve e como todas as coisas, toda inteira no presente” (Merleau-Ponty 4, p.319-320, nota 1 [644-645, nota 47]). Essa crítica é retomada nas 
páginas sobre a temporalidade (Merleau-Ponty 4, p.474-475, nota 1 [652-653, nota 3]), onde Merleau-Ponty introduz a noção husserliana de síntese ${ }^{7}$ :

"Síntese passiva do tempo - uma expressão que evidentemente não é uma solução, mas um índice para designar o problema (...). Falando em síntese passiva, queríamos dizer que o múltiplo é penetrado por nós e que, todavia, não somos nós que efetuamos sua síntese" (Merleau-Ponty 4, pp. 479 [561]; 488 [572]).

Além disso, Merleau-Ponty julga que Bergson conhece somente o "corpo objetivo", mas ignora o "corpo fenomenal” (Merleau-Ponty 4, p.493 [578]); compreende a consciência antes como "conhecimento" que como "existência", fazendo do tempo uma "sucessão de agoras" (aquilo que Heidegger chamava de "tempo nivelado ou vulgar"); e ignorou o "movimento único pelo qual se constituem as três dimensões do tempo" (Merleau-Ponty 4, p. 471 [552]). Sendo assim, Bergson não estaria completamente certo, embora sua idéia esteja correta, aquela pela qual o corpo e o espírito se comunicam pela mediação do tempo.

No capítulo sobre a temporalidade, Merleau-Ponty mostra que o tempo não é compreensível a partir das coisas nem do ser: "aquilo que falta ao próprio ser para ser temporal, é o não-ser do alhures, do outrora e do amanhã" (Merleau-Ponty 4, p. 471). Se o tempo não é compreensível a partir das coisas, tanto menos o será a partir de uma consciência que teria o modo de ser de uma coisa e padeceria da mesma saturação de ser. Donde a crítica da teoria do engramme, teoria segundo a qual haveria uma conservação somática ou corporal do passado. Nunca um traço presente poderá explicar a retroreferência, isto é, o visar de um passado como passado. Merleau-Ponty também censura Bergson por ter cometido exatamente o mesmo erro que a teoria que ele critica:

"Vimos que a melhor razão para rejeitarmos a conservação fisiológica do passado também nos autoriza a rejeitar sua 'conservação psicológica'. Esta razão é uma espécie de conservação, porém nenhum 'traço' psicológico ou físico do passado pode fazer-nos compreender a consciência que temos do passado" (Merleau-Ponty 4, p. 472 [553]).
Bergson dá conta da retro-referência pela conservação das nossas percepções ou, como objeta Merleau-Ponty, por meio de uma percepção conservada que "está sempre no presente, ela não abre à nossa frente essa dimensão de fuga e de ausência que é o passado" (Merleau-Ponty 4, p.473 [554]). Tendo excluído o não-ser da vida da consciência, Bergson não consegue dar conta da constituição do tempo nem superar as teorias que ele mesmo critica. E a crítica de Merleau-Ponty a Bergson se conclui assim:

"Quando ele diz que a duração faz 'bola de neve consigo mesma', quando no inconsciente ele acumula lembranças em si, ele forma o tempo com o presente conservado, a evolução com o evoluído" (Merleau-Ponty 4, p. 474-475, nota 1 [652-653, nota 3]).

O defeito irremediável da concepção bergsoniana do tempo é, segundo Merleau-Ponty, querer constituir o tempo com o presente. Essa crítica merleau-pontiana de Bergson nos parece bastante problemática porque Merleau-Ponty parece atribuir a Bergson uma espécie de dualismo, não mais um dualismo de corpo e alma, mas um dualismo consciente - inconsciente. Na medida em que todo o esforço do pensamento bergsoniano é precisamente para sair do dualismo, o tema das lembranças que poderiam ser conservadas no inconsciente parece-me mais próximo de Freud que de Bergson. ${ }^{8} \mathrm{Se}$ o passado, como disse Bergson, se conserva a si mesmo automaticamente, ele aparece ao campo de consciência no modo de virtualidade e não precisa deixar um traço em algum lugar particular para conservar-se. Mais adiante, nas notas inéditas de fevereiro de 1959, Merleau-Ponty reencontrará toda a originalidade do pensamento de Bergson:

"Bergson. Mostrar o valor das "imagens" como aquilo que exprime o ser [von Selbst], a identidade do [Seyn et Vernehmung Einführung de Heidegger, 16]. Isso mostra o contato bergsoniano com o Ser e dá o sentido profundo da reabilitação do tempo, da identificação Ser-tempo em Bergson. Insistir sobre o heraclitismo de Bergson. A reabilitação do tempo e do Ser von selbst como remanescente da metafísica a título de experiência. A mudança de sentido de Bergson. Para os contemporâneos "espiritualista"; para nós, aquilo que é válido em Bergson é, ao contrário, o 
sentimento de um pensador do ser. Confrontar essa intuição com as considerações, bastante pobres, das Duas fontes sobre a história humana. Retomar a crítica da idéia do nada. Digamos que ele tem razão ao refutar a idéia do nada, mas errou tão somente por não ter visto que o ser que resiste à negação da intuição do nada não é o ser « positivo», mas o Seyn". 9

A obra A natureza, que reúne os cursos de Merleau-Ponty no Collège de France, expressa de maneira mais nítida a simpatia intelectual entre Merleau-Ponty e Bergson. Com efeito, o que Merleau-Ponty procura em Bergson é precisamente um caminho para escapar da tradição constante em filosofia desde Santo Agostinho, aquela que faz refluir o tempo para o lado do sujeito, na forma de "expectativa, atenção e recordação" (Santo Agostinho 9, XI, 28, §37), conceitos que guardam certa semelhança com a retenção e protensão husserlianas. Mas para além ou para aquém do tempo "serial", conforme a expressão de Whitehead, haveria um "tempo inerente à Natureza". Esse tempo levará Merleau-Ponty a postular uma "subjetividade da Natureza", aquela que estaria "presa na engrenagem de um tempo cósmico" (Merleau-Ponty 5, p. 194). Em contrapartida, uma natureza que não tenha em si mesma absolutamente nada do passado nem do futuro seria uma "Natureza-flash, (...) um relâmpago pontual continuado, que não é nada que se possa viver" (Ibid., p. 195). Do ponto de vista da vida, pensar no tempo implica reconhecer — como fez Merleau-Ponty — que não somos autores dos nossos próprios batimentos cardíacos. No limite, não fomos nós que escolhemos nascer. Essa intuição pode passar despercebida na Fenomenologia, mas em A Natureza, o autor lhe imprime uma significação mais abrangente: "Existe uma passagem natural do tempo, a pulsação do tempo não é uma pulsação do sujeito, mas da Natureza, ela atravessa a nós, espíritos” (Ibid.). Eis aqui que o conceito husserliano de "intencionalidade operante" adquire uma relevância sempar, como reenvio do fenômeno à totalidade (multiplicidade) de todos os fenômenos ou noemas não dados. Ao constatar certa "pregnância da significação nos signos" (MerleauPonty 4, p. 490 [575]), podemos considerar o mundo como o "berço das significações", ou seja, como a condição de possibilidade da "intencionalidade de ato", àquela que supõe a atividade de um ego, isto é, de um sujeito. Nesse sentido, Damon Moutinho sugere que essa é também a "condição pela qual Merleau-Ponty poderá dizer que o tempo não é para alguém, mas que ele é alguém" (Moutinho 7, p. 42). Assim, segundo Damon, o que permite caracterizar o "cogito pré-reflexivo merleaupontiano" é a transição do sujeito ao tempo, ou seja, a temporalidade: "o sujeito da intencionalidade operante, em ação em todo o sistema eu-outrem-mundo, é o tempo" (Ibid., p. 21). Esse quadro conceitual não estaria completo sem a noção de "presença". Como vimos, Bento Prado Jr. chamou a atenção para o campo perceptivo, mostrando que este remete necessariamente a outros objetos e sem ele o objeto percebido não poderia sequer vir a minha presença: "É sob essa reserva que se deve chamar a Natureza de uma presença operante" (Merleau-Ponty 5, p. 197), expressão que Merleau-Ponty toma emprestada de Wahl (Wahl 10, p. 168).

Há, portanto, uma relação entre o cogito tácito e a subjetividade da natureza, de modo que o "abandono" do primeiro em benefício do segundo não pode ser considerado uma ruptura, mas sim uma evolução do pensamento de Merleau-Ponty, que caminha de uma concepção ainda marcada pelos vestígios da reflexão (cogito tácito — ênfase na palavra sublinhada) para uma instância mais marcadamente pré-reflexiva. O cogito tácito, por sua vez, já assinala o enfrquecimento da reflexividade tradicional (consciência constituinte) em proveito de uma subjetividade alargada (“da natureza”). Não há passagens abruptas no pensamento de Merleau-Ponty, mas uma maturação crítica que redunda na transformação das noções e se encaminha para uma diluição do cogito como sinônimo de consciência.

\section{Considerações finais}

Na conferência "A percepção da mudança”, Bergson propõe outra metáfora para mostrar-nos como devemos compreender a duração e a multiplicidade de interpenetração:

"Escutemos uma melodia. (...) Se recortamos em notas distintas, em tantos 'antes' e 'depois' quantos nos aprouver, é porque nela misturamos imagens espaciais e porque impregnamos de simultaneidade a sucessão: no espaço, e apenas no espaço, há distinção nítida de partes exteriores umas às outras" (Bergson 3, p. 172-173). 
Compreender esse ponto exige que encaremos o passado de modo inteiramente diferente do que fomos acostumados a fazê-lo pela filosofia e pela linguagem. Com efeito, o que significa "conservar"? E o que é, ao certo, o presente? Merleau-Ponty explica o surgimento de um "presente novo" como a "passagem de um futuro ao presente e do antigo presente ao passado", afirmando que "é com um só movimento que, de um extremo ao outro, o tempo se põe a mover" (Merleau-Ponty 4, p. 479 [561]). Desse modo, pretendese superar a concepção bergsoniana de uma "multiplicidade de fenômenos ligados" ao substituí-la por um único "fenômeno de escoamento":

"O tempo é o único movimento que em todas as suas partes convém a si mesmo, assim como um gesto envolve todas as contrações musculares que são necessárias para realizá-lo" (Merleau-Ponty 4, p. 479 [562]).

Embora seja este o momento em que mais parece abrir-se uma brecha entre Merleau-Ponty e Bergson, marcada pelas recorrentes alusões a Heidegger ${ }^{10}$, pensamos que, na verdade, o que se verifica é uma identificação entre ser e tempo, que o aproxima ainda mais de Bergson: "como no tempo ser e passar são sinônimos, tornando-se passado o acontecimento não deixa de ser" Merleau-Ponty 4, p.480 [563]). Todavia, MerleauPonty insiste e focaliza seu ataque:

"Bergson estava errado em explicar a unidade do tempo por sua continuidade, pois isso significa confundir passado, presente e porvir sob o pretexto de que se caminha de um para o outro por transições insensíveis, e enfim significa negar o tempo" (MerleauPonty 4, p. 481 [563]).

O que Bergson defende, de fato, é que o passado conserva-se por si mesmo automaticamente. O passado, para ele, é a parte de nossa história que não interessa mais à nossa ação presente e as "lembranças" serviriam para simplificar uma experiência anterior e assim completar a experiência do momento (Bergson 3, p. 177). Podemos interpretar o argumento de Bergson seguindo os passos de Bento Prado Jr. Se a percepção consciente é um recorte parcial na totalidade do "campo transcendental" de imagens, isto é, um "empobrecimento da presença"; a memória não deveria ser compreendida como alguma coisa que vá buscar lembranças no inconsciente, senão como um "filtro" que deixa passar — e, nesse sentido, também "recorta" — a partir de um "campo virtual" de passado as lembranças que podem interessar-nos no presente. Nesse processo, destaca-se o papel do cérebro: "O cérebro serve aqui para operar uma escolha no passado, para diminuí-lo, simplificá-lo, utilizá-lo, mas não para conservá-lo” (Bergson 3, p. 178). Temos por hábito acreditar que o passado é "abolido" e é precisamente essa crença que nos impede aceitar a constatação mais evidente: “a conservação do passado no presente não é nada além da indivisibilidade da mudança" (Bergson 3, p. 179).

Antes de concluir este artigo, podemos indicar algumas observações pertinentes. Em primeiro lugar, a nova relação que se estabelece entre sujeito e objeto a partir de uma "visão universal do devir". Merleau-Ponty descrevia um "ambiente movente que se distancia de nós, assim como a paisagem na janela do vagão" (Merleau-Ponty 4, p. 480 [562]). E Bergson, indo além, sustentava que "o objeto e o sujeito devem estar um em face do outro numa situação análoga à de dois trens" (Bergson 3, p. 181), que se movem na mesma velocidade e no mesmo sentido, na qual duas pessoas, estando uma em cada trem, poderiam se dar a mão pela janela. Por isso a metáfora da "bola de neve" é importante. Ela supõe uma concepção de filosofia a partir da qual "podemos nos habituar a não isolar nunca o presente do passado que ele arrasta consigo" (Ibid.). Nesse sentido, a bola de neve também anuncia uma das noções mais importantes de Bergson, o elã vital: "Um grande elã carrega todos os seres e todas as coisas. Por ele nos sentimos levantados, arrastados, carregados" (Bergson 3, p. 182). Interessante notar que MerleauPonty também sabia disso:

" $E u$ nunca tenho consciência de ser o autor absoluto do tempo, de compor o movimento que vivo, parece-me que é o próprio movente que se desloca e que efetua a passagem de um instante ou de uma posição à outra" (Merleau-Ponty 4, pp. 319-320, nota 1 [371, nota 47]). 
Por último, na obra "Introdução à metafísica" (Bergson 3), Bergson vai mostrar que os conceitos adotados pela filosofia nem sempre se adaptam bem aos objetos que desejamos conhecer. Muitas vezes, os conceitos são amplos demais para se ajustarem com exatidão aos entes reais. Isso ocorre de forma paradigmática no caso do tempo, por isso em lugar de explicar o que é o tempo por meio de conceitos como "unidade", "multiplicidade", "síntese" e outros que geralmente vem aos pares (continuidadedescontinuidade, quantidade-qualidade, homogêneo-heterogêneo, identidade-diferença e assim por diante) convém adotar a metáfora. Algumas delas, em conjunto, poderão aproximar-nos de uma "intuição da duração". Assim como a da "bola de neve", a metáfora do "fio do novelo" também cumpre essa função:

"Imaginemos antes um elástico infinitamente pequeno, contraído, se isso fosse possível, num ponto matemático. Estiquemo-lo progressivamente de modo que faça com que do ponto saia uma linha que irá sempre aumentando. Fixemos nossa atenção, não sobre a linha enquanto linha, mas sobre a ação que a traça. Consideremos que, a despeito de sua duração, essa ação é indivisível, se supomos que se realiza sem parar; que, se nela intercalamos uma parada, faremos dela duas ações ao invés de uma e que cada uma dessas ações será então o indivisível de que falamos; que não é nunca a própria ação que é divisível, mas a linha imóvel que ela deposita embaixo de si como um rastro no espaço, Libertemo-nos por fim do espaço que subentende o movimento para só levar em conta o próprio movimento, o ato de tensão ou de extensão, enfim, a mobilidade pura. Teremos desta vez uma imagem mais fiel de nosso desenvolvimento na duração" (Bergson 3, p. 191).

A partir deste exemplo e dependendo do ponto de vista que adotemos, poderemos admitir que a descrição trata de uma unidade - caso consideremos o movimento que progride - ou de uma multiplicidade — caso privilegiemos os estados que se esparramam. Mas mesmo assim não esgotaremos a realidade movente que deu origem a essas duas concepções antagônicas.

Neste primeiro mergulho no universo merleau-pontiano, identificamos uma crítica de Merleau-Ponty a Bergson e procuramos rebatê-la com base na argumentação bergsoniana. Percebemos assim que não há propriamente uma confluência em relação à concepção do tempo que ambos os filósofos defendem, mesmo porque para Bergson o tempo não deveria ser uma "questão" filosófica e sim um "dado imediato", tanto da subjetividade como da realidade objetiva. Nesse sentido, nossa conclusão se encaminha para o reconhecimento de que a leitura que Merleau-Ponty faz de Bergson, na Fenomenologia da percepção, coloca o tempo no registro da subjetividade. Não obstante, o intuito de Bergson é precisamente elucidar a identificação entre ser e tempo (registro ontológico), anterior à separação conceitual entre o subjetivo e o objetivo. Por isso, a duração, como uma bola de neve, acumula, mas também dispersa à medida que vai se gastando. Trata-se de um processo de diferenciação na temporalidade sem espacialização, ou seja, sem separação. Essa diferenciação, portanto, admite unidade e multiplicidade. Talvez por isso, na Fenomenologia da percepção, notamos um Merleau-Ponty mais confuso quanto à Bergson. Porém, o Merleau-Ponty das notas de trabalho e do curso sobre a natureza assume uma atitude, por assim dizer, mais bergsoniana. Mas isso é tema para outro artigo. ${ }^{11}$

\section{REFERÊNCIAS BIBLIOGRÁFICAS}

1. BERGSON, H. Matéria e memória. São Paulo: Martins Fontes, 2006.

2. A evolução Criadora. São Paulo: Martins Fontes, 2005.

3._O Pensamento e o movente. São Paulo: Martins Fontes, 2006.

4.MERLEAU-PONTY, M. Phénoménologie de la Perception. Paris: Gallimard, 1997. [Trad. brasileira Merleau-Ponty, M. Fenomenologia da percepção. São Paulo: Martins Fontes, 2006.] 
5. . A Natureza. São Paulo: Martins Fontes, 2006.

6. MOURA, C. A. Racionalidade e crise: estudos de história da filosofia moderna e contemporânea. São Paulo: Discurso Editorial; Editora da UFPR, 2001.

7. MOUTINHO, D. "Tempo e sujeito - O transcendental e o empírico na fenomenologia de Merleau-Ponty”, in: DoisPontos, v. 1, n. 1, 2004.

8. PRADO JÚNIOR, Bento. Presença e campo transcendental: consciência e negatividade na filosofia de Bergson. São Paulo: Edusp, 1988.

9. SANTO AgOStinHO. Confissões, in: Pensadores. São Paulo: Abril Cultural, 1973. 10. WAHL, J. Vers le concret. Paris: Vrin, 1932.

\section{Merleau-Ponty and the snowball: compliment and criticism to Bergson}

Abstract: This paper examines some approaches and differences of the Merleau-Ponty's philosophy in relation to that of Bergson, once that Merleau-Ponty seems to be divided about the bergsonian conception of time in his thinking. This oscillation between criticism and compliment is certainly visible in the Phenomenology of perception, in which Merleau-Ponty recognizes that Bergson would have dissolved the question of the dualism when affirming that "the body and the spirit communicates by mediation of the time". However, Merleau-Ponty denounces another kind of bergsonian dualism, that intends to find the unit in the multiplicity by means of the concept of "fusing multiplicity". In this sense, the bergsonian metaphor of the "snow ball" looks for to characterize the essence of the time as duration.

Keywords: Merleau-Ponty, Bergson, temporality, dualism, subjectivity.

\section{NOTAS}

1. As passagens traduzidas para o português correspondem à edição brasileira. MerleauPonty. Fenomenologia da percepção. São Paulo: Martins Fontes, 2006. Indicamos a paginação dessa obra entre colchetes [p. 106].

2. Cf. Moutinho 7, p. 19: "É só nessa medida que o campo fenomenal pode ser "convertido" em campo transcendental e o ser no mundo ser coroado com um ser para si: é preciso que o ser no mundo e, com ele, todo o sistema de horizontes da percepção, seja arrastado por essa nova reflexão e levado à consciência de si. E se essa reflexão não implica pôr uma consciência transcendental que possa pensar o sistema na integralidade, é porque estamos aqui não no plano da intencionalidade de ato, mas no plano da intencionalidade operante, 'aquela que faz a unidade natural e antepredicativa do mundo e de nossa vida' (Merleau-Ponty, 1995, p. XIII): é ela que assegura o sistema de reenvios que arrasta todo o sistema".

3. Cf. Moura, C. A. "A cera e o abelhudo: expressão e percepção em Merleau-Ponty” (Moura 6, p.262). 4. Cf. Moura, C. A. Curso de História da filosofia contemporânea. São Paulo: FFLCH-USP, 2008

5. Entre o que designamos como físico ou como corpo e o que chamamos de espírito ou consciência não haveria oposição de natureza, mas de graus de tensão da duração. Uma duração infinitamente distendida corresponderia àquilo que chamamos de extensão; uma duração infinitamente tensa e contraída corresponderia àquilo que chamamos de inextenso ou de consciência. O núcleo da ontologia bergosiana revela uma realidade que é pura duração e se apresenta em diferentes ritmos de tensão (Cf. Leopoldo e Silva, F. Curso de História da filosofia contemporânea. São Paulo: FFLCH-USP, 2007).

6. Bergson usa a metáfora da "bola de neve" numa passagem do primeiro capítulo de $A$ evolução criadora: "Tomemos o mais estável dos estados internos, a percepção visual de um objeto exterior imóvel. (...) Minha memória está aí, empurrando algo desse passado para dentro desse presente. Meu estado de alma (...) infla-se continuamente com a duração que ele vai juntando; por assim dizer, faz bola de neve consigo mesmo. (...) A verdade é que mudamos incessantemente e que o próprio estado já é mudança" (Bergson 2, p. 2).

7. Na conferência "La raison incarnée - pensée et sensibilité chez MerleauPonty» (São Carlos: UFSCar, 2008), Pascal Dupond mostra que Merleau-Ponty faz justiça à noção kantiana de "synthèse", reinterpretando-a a partir da noção de "synopsis", também kantiana.

8. Bergson parece confirmar esse ponto, mas não vamos aprofundar o tema aqui. Limitemo-nos a assinalar um possível desdobramento da pesquisa. Em relação à psicopatologia, hoje cindida em psicanálise e psiquiatria, Bergson abre um terreno fértil para a discussão, lembrando que a função do cérebro não seria pensar, senão impedir que o pensamento se perca no sonho. Nesse sentido, o cérebro seria o órgão de atenção a vida: "Para nos limitarmos a essa última ciência, mencionaremos simplesmente a importância crescente que assumiram progressivamente as considerações de tensão psicológica, de atenção à vida, e tudo o que está envolvido no conceito de esquizofrenia. Nem mesmo nossa idéia de uma conservação integral do passado deixou de encontrar cada vez mais sua verificação empírica no vasto conjunto de experiências instituído pelos discípulos de Freud.” (Bergson 3, p. 84). Essa idéia, à primeira vista, parece bastante contemporânea da teoria do inconsciente.

9. Nota gentilmente cedida pelo Prof. Dr. Pascal Dupond (Universidade de Toulouse). 
10. A noção heideggeriana de ek-stase, entendida como uma "fuga geral para fora do Si, a lei única desses movimentos centrífugos" (Merleau-Ponty 4, p.480 [p. 562]), levará Merleau-Ponty a afirmar uma identidade entre "afetante" e "afetado": "O ímpeto do tempo é apenas a transição de um presente a um presente. Este ek-stase, esta projeção de uma potência indivisa em um termo que lhe está presente, é a subjetividade" (Merleau-Ponty 4, p. 487 [p. 571]).

11. Agradeço à equipe de pareceristas dos «Cadernos Espinosanos «pela leitura do texto e pelas valiosas sugestões.
PROUST À LUZ DE FREUD - UMA LEITURA MERLEAU-

PONTYANA ${ }^{*}$

\section{Ronaldo Manzi**}

Resumo: pretendo abordar de modo breve como, diferentemente da tradição francesa, MerleauPonty leu Proust à luz freudiana, podendo, assim, insistir num problema fundamental da sua fenomenologia: a temporalidade. Para tal abordagem, realizarei um exame da possível intersecção do caso do membro fantasma com a noção de sedimentação descrita pelo filósofo. Com esse procedimento, compreenderemos o recurso de Merleau-Ponty aos escritos de Proust, notadamente, ao conceito de "tempo". Veremos, entretanto, que este recurso está largamente em interface com noções da clínica freudiana.

Palavras-chave: tempo perdido; sedimentação; temporalidade; membro fantasma; fenomenologia.

É bastante conhecida a passagem da Phénoménologie de la Perception onde Merleau-Ponty busca compreender a experiência do "membro fantasma". Há um paradoxo nessa experiência que não deixa de nos assombrar até hoje e que instigou diversos outros pesquisadores a pensar nessa estranha manifestação. Desde Jasper (7, p. 111), por exemplo, essa experiência exigia uma compreensão do sentido da conduta para além das suas diferentes manifestações que não poderiam ser reduzidas a um simples déficit ou distúrbio fisiológico do indivíduo, pois envolve o próprio sentido do que seria a relação do sujeito com a percepção e/ou imaginação totalitárias de si. Autores como Lhermitte (cf. Lhermitte 9) e Schilder (cf. Schilder 12), sobre os quais Merleau-Ponty se debruçou longamente, mostram isso com clareza.

Entretanto, é verdade que essa questão nos leva também diretamente a uma reflexão sobre a temporalidade do sujeito juntamente com sua "história pessoal". Não poderíamos deixar de notar, seguindo as análises freudianas, por exemplo, que há transtornos das significações afetivas que poderiam "barrar" o sujeito, se assim podemos

* Este texto foi apresentado no dia 17 de novembro de 2008, na Jornada "Merleau-Ponty e o Grande Racionalismo" (realizado na Universidade de São Paulo).

** Doutorando em filosofia pela Universidade de São Paulo. 